\title{
Study on thermodynamics of glycerol hydrogenolysis to high value-added diols
}

\author{
Liping Liu*, Yu Cui, Shuo Chen, Shuqi Fang \\ School of mechanical and power engineering, Zhengzhou University, Zhengzhou, Henan, 450001, China
}

\begin{abstract}
The thermodynamic process on hydrogenolysis of glycerol to high value-added diols was studied. The thermodynamic parameters of the main reaction equations were calculated, and the effects of temperature, pressure and molar ratio of hydrogen to glycerol on the products of the reaction equilibrium system were analysed. The deep hydrogenolysis system of glycerol and the degradation of its diols are also discussed. The results show that temperature has a great influence on the selectivity of the products. 1,2propanediol is more easily formed. The optimum conditions for hydrogenolysis of glycerol to 1,2propanediol are $400-500 \mathrm{~K}$ and the molar ratio of hydrogen to glycerol of 1.0-1.5. The calculated results are compared with the related experimental results.
\end{abstract}

\section{Introduction}

With the rapid development of biomass energy, the byproduct glycerin of biodiesel will be overproduced. The development of new ways of glycerol transformation can balance the supply and demand of glycerol market and realize the efficient utilization of biological resources. The preparation of binary alcohol by catalytic hydrogenolysis of glycerol can provide high additional value of the product. 1,2-propanediol and 1,3propanediol are important chemical raw materials. Traditional production methods of propylene glycol are all based on petroleum products. The catalytic hydrogenation of glycerol to propylene glycol is characterized by rich raw materials, renewable, low cost, clean and pollution-free [1].

At present, the research of glycerol hydrogenolysis is mainly in the preparation of catalyst. The catalysts for glycerol hydrogenolysis include $\mathrm{Cu}, \mathrm{Ni}, \mathrm{Ru}, \mathrm{Rd}, \mathrm{Pt}$ and so on. The selectivity of products is different with different catalysts. Due to the complex reaction system of glycerol hydrogenolysis, there are few related thermodynamics studies. Kun Ouyang et al. [2] calculated the thermodynamic parameters of the reaction equation for the coupling process of glycerol aqueous phase reforming (APR) and glycerol catalytic hydrogenation, taking into account 1,2-propanediol and 1,3-propanediol. However, the equilibrium products of hydrogenolysis of glycerol have not been analyzed in this study.

The thermodynamic analysis of the catalytic hydrogenolysis of glycerol to diols can provide a reference for the optimization of catalytic process. 1,2propanediol, 1,3-propanediol and glycol are three important diols in the reaction system of glycerol hydrogenolysis. In this paper, the thermodynamics of the glycerol hydrogenolysis to diols is analyzed, the thermodynamic parameters of the main reaction equations are calculated, and the effects of reaction conditions on the equilibrium products of the reaction system are discussed. In addition, the thermodynamics of glycerol deep hydrogenolysis system was also analyzed.

\section{Calculation principles and methods}

\subsection{Main reaction of glycerol hydrogenation to diol}

According to literature [3], the main reactions of glycerol catalytic hydrogenolysis to produce 1,2-propanediol, 1,3propanediol and glycol are shown in Table 1. 
Table 1. Main reactions of glycerol hydrogenolysis to diols.

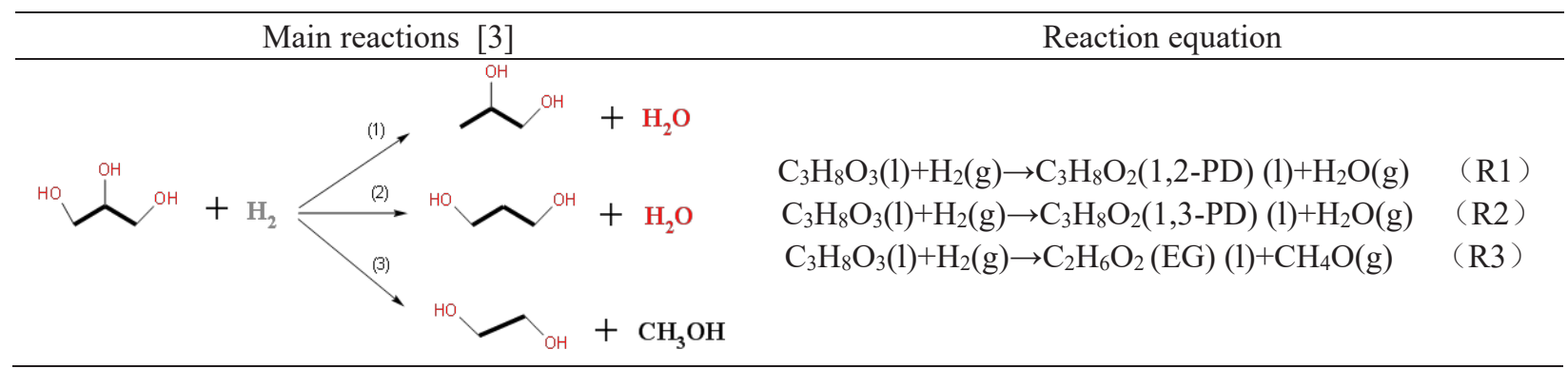

It can be seen from Table 1 that 1,2-propanediol and 1,3-propanediol are generated from the dehydration of glycerol, and glycol and methanol are generated from the hydrocracking of glycerol. The actual hydrogenation reaction condition is complex, and here a simplified reaction system (SRS) for hydrogenation of glycerol to diols was established by equation (R1-R3). The components (code) of the system include glycerol (GL), hydrogen $\left(\mathrm{H}_{2}\right)$, 1,2-propanediol (1,2-PD), 1,3propanetriol (1,3-PD), glycol (EG), methanol $(\mathrm{MeOH})$.

\subsection{Research method and parameter determination}

The thermodynamic parameters of the reaction were calculated by HSC chemistry. The equilibrium products of glycerol hydrogenation system were calculated by Gibbs reactor model of Aspen Plus software. The physical property equation of PENG-ROB formula was used.

The parameters used in the thermodynamic analysis are the conversion of glycerol or hydrogen and the selectivity of products containing carbon, which are defined as follows:

$$
\begin{aligned}
& X(i)=\left[\left(F_{j, \text { in }}-F_{j, \text { out }}\right) / F_{j, \text { in }}\right] \times 100 \% \\
& S(j c)=\left[\frac{M}{3} F_{j c, \text { out }} /\left(F_{G L, \text { in }} F_{G L, \text { out }}\right)\right] \times 100 \%
\end{aligned}
$$

Where, $X(i)$ is the conversion rate of raw material $\mathrm{i}$ (glycerol or hydrogen), \%. $F_{j}$ is the molar flow rate of product j, $\mathrm{kmol} / \mathrm{hr} . \quad S(\mathrm{jc})$ is the selectivity of carbonaceous material, \%. The subscript of ' $i$ ' is the raw material (glycerol or hydrogen); the subscripts of 'in' and 'out' are the state of reaction and equilibrium production respectively; the subscript ' $\mathrm{jc}$ ' is a component of 1,2-propanediol (1,2-PD), 1,3-propanetriol (1,3-PD), glycol (EG) and methanol $(\mathrm{MeOH})$ in the carbon containing product. $\mathrm{M}$ is the number of carbon in the molecule of the product containing carbon.

\section{Results and discussion}

\subsection{Effect of reaction temperature on thermodynamic parameters}

The changes of reaction enthalpy $(\triangle H r)$, Gibbs free energy $(\triangle G r)$ and chemical equilibrium constant $\left(\mathrm{K}_{\mathrm{P}}\right)$ with temperature were calculated in the range of 300-600 $\mathrm{K}$. The effects of reaction temperature on the thermodynamic parameters of each reaction are shown in Figure 1.

Figure 1(a) shows that in the glycerol hydrogenation system, the molar enthalpy changes of reactions (R1, R2) decrease with the increase of temperature. The reactions $(\mathrm{R} 1, \mathrm{R} 2)$ are exothermic, and the exothermic heat is more than $40 \mathrm{~kJ} / \mathrm{mol}$, which belongs to strong exothermic reaction. The reaction (R3) is endothermic, and the change of reaction enthalpy slightly decreases with the increase of temperature. According to Figure 1(b), the Gibbs free energy change of reaction (R1) basically does not change with temperature, and the value of $\triangle G r$ is about $-75 \mathrm{~kJ} / \mathrm{mol}$. The Gibbs free energy changes of the reactions (R2, R3) decrease with the increase of temperature. The Gibbs free energy changes of the three reactions in the temperature range are all less than zero, which can be spontaneous. From Figure 1(c), the reaction temperature has a great influence on the equilibrium constants of each reaction. The reactions (R1, R2) have high equilibrium constant, and their equilibrium constants decrease with the increase of temperature. The equilibrium constant of 1,3-propanediol is higher than that of 1,2-propanediol at high temperature. The results show that 1,2-propanediol and 1,3propanediol are easier to form than glycol in thermodynamics, and the formation of 1,2-propanediol and 1,3-propanediol is more favourable at low temperature. By comparing the calculated results with the values of the relevant thermodynamic parameters [2], it is found that the calculated results are close to the data after the analysis of the thermodynamic parameters of the relevant equations. 


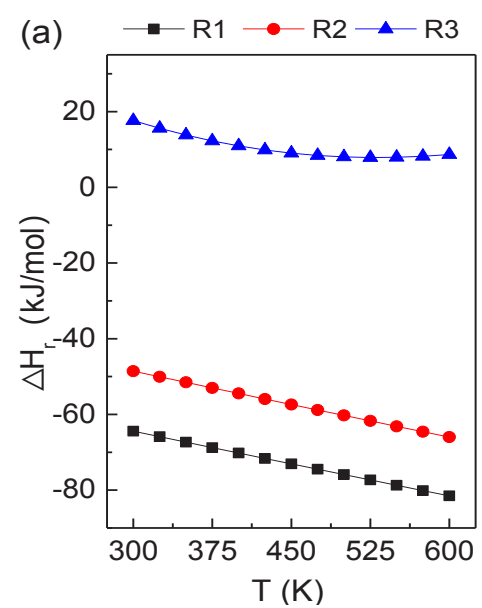

(a) $\Delta H r$

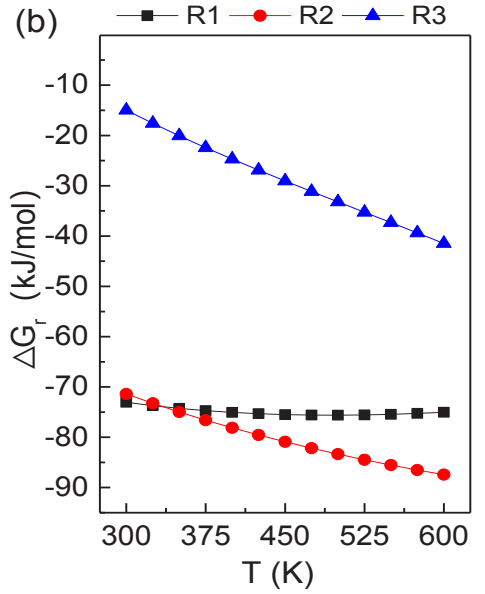

(b) $\Delta G r$;

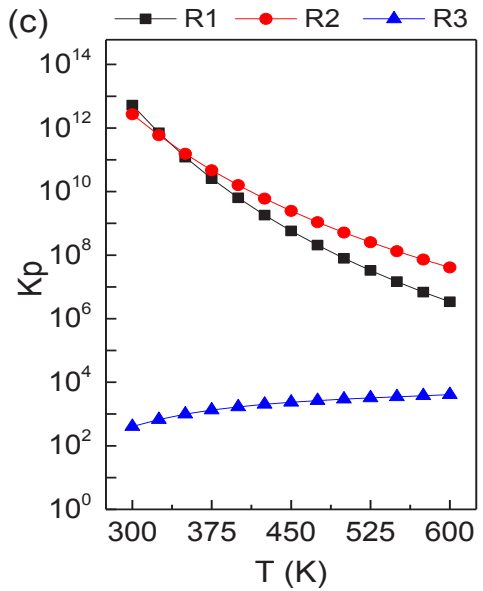

(c) $K p$.

Figure 1. Effect of reaction temperature on thermodynamic parameters of each reaction.

\subsection{Effect of reaction conditions on the simplified reaction system (SRS)}

The effects of temperature $(300-600 \mathrm{~K})$, pressure $(0.1$ 12.0 $\mathrm{MPa})$, molar ratio of hydrogen to glycerol $(0.2-2.0)$

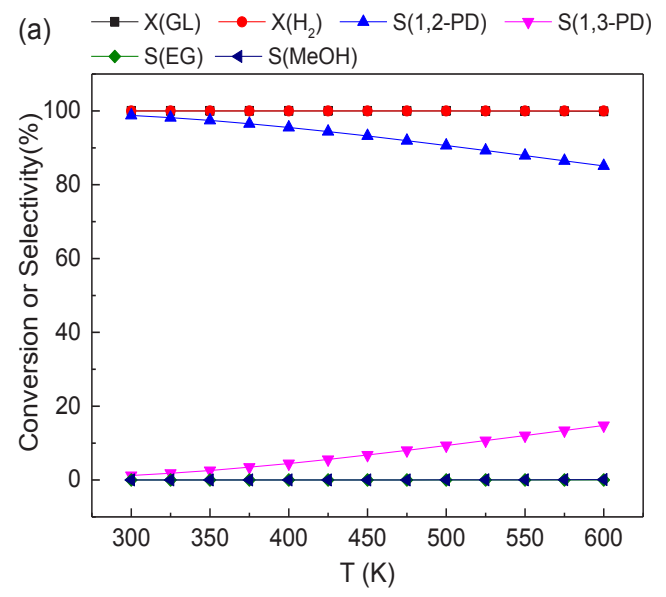

Reaction conditions:

(a) $3.0 \mathrm{MPa}, \mathrm{H}_{2} / \mathrm{GL}=1.0$;

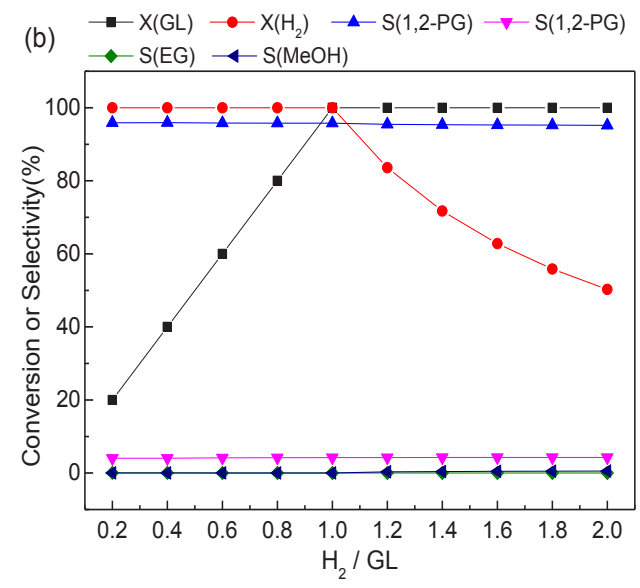

(b) $398 \mathrm{~K}, 3.0 \mathrm{MPa}$. simplified reaction system (SRS) are shown in Figure 2.

on the conversion of raw material and the selectivity of products containing carbon were analysed. The effects of reaction conditions on the equilibrium products of the

Figure 2. Effects of reaction conditions on the simplified reaction system (SRS).

Figure 2(a) shows under the reaction conditions, the conversion rates of glycerol and hydrogen are very high, almost $100 \%$. With the increase of reaction temperature, the selectivity of 1,2-propanediol decrease and the selectivity of 1,3-propanediol increase. Glycol has the lowest selectivity. From Figure 2(b), the molar ratio of $\mathrm{H}_{2}$ to glycerol (GL) is equal to 1.0 as the turning point. Before this point, the conversion rate of glycerol increases, and the conversion rate of hydrogen is close to $100 \%$. After this turning point, the conversion rate of glycerol is $100 \%$, and the conversion rate of hydrogen decreases. In Figure (b), the molar ratio of hydrogen to glycerol has little effect on the selectivity of the three diols. The order of product selectivity under the calculated conditions is: 1,2-propanediol $>1,3-$ propanediol $>$ glycol. It is also found that the pressure has little effect on the conversion of raw materials and product selectivity in the simplified reaction system (SRS).

\subsection{Effect of reaction conditions on the deep hydrogenolysis system of glycerol (DHS)}

For the deep hydrogenolysis system of glycerol, the products are complex in the reaction process. There are dehydration reaction, hydrogenation reaction, hydrogenolysis reaction and condensation reaction. A typical mechanism of glycerine deep hydrogenolysis is proposed in reference [4], as shown in Figure 3. 


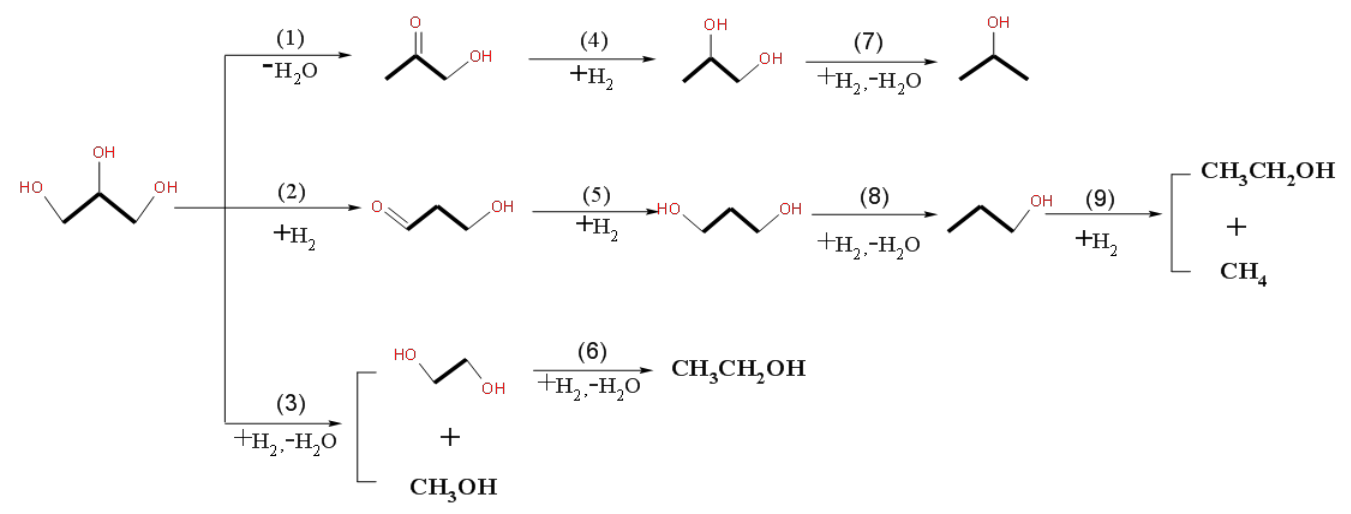

Figure 3. Mechanism of glycerol deep hydrogenolysis system [4].

According to the mechanism of Figure 3, a deep hydrogenolysis system (DHS) of glycerol was established. The main reactions or substances (code) in this system include: dehydration of glycerol to generate hydroxyacetone (Acetol), hydrogenation of glycerol to generate 3-Hydroxypropionaldehyde (3-HPA). 1,2propanediol (1,2-PD), 1,3-propanediol (1,3-PD) and ethylene glycol (EG) are the binary alcohols in the hydrogenolysis of glycerol. The binary alcohols are further hydrogenated and degraded into monohydric alcohols: n-propanol (1-PO), isopropanol (2-PO), ethanol $(\mathrm{EtOH})$ and methanol $(\mathrm{MeOH})$. In case of further hydrogenolysis of monohydric alcohol, the final product of monohydric alcohol is methane [5] after replacement and fracture of $\mathrm{C}-\mathrm{C}$ bond and $\mathrm{C}-\mathrm{O}$ bond for many times, in addition to carbon monoxide, carbon dioxide and water.

The effects of temperature $(300-600 \mathrm{~K})$, pressure (0.1-12.0 MPa), molar ratio of hydrogen and glycerol (110) on the conversion of raw materials and the selectivity of products were analyzed. The effects of reaction conditions on the deep hydrogenolysis system (DHS) are shown in Figure 4.

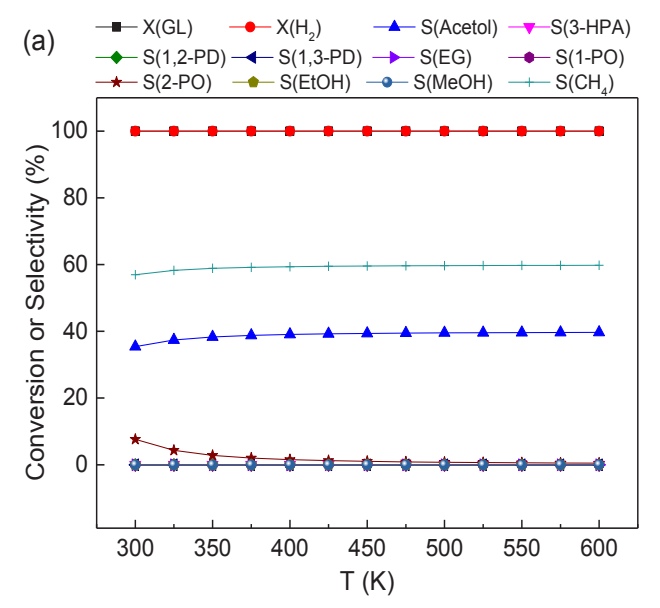

Reaction conditions: (a) $\mathrm{H}_{2} / \mathrm{GL}=3.0,3.0 \mathrm{MPa}$; (b) $500 \mathrm{~K}, 3.0 \mathrm{MPa}$.
Figure 4 shows that the thermodynamic conversion rate of glycerol is basically $100 \%$. The selectivities of methane and hydroxyacetone are high. From Figure 4(a), isopropanol (2-PO) also has a slightly higher selectivity at low temperature, while the selectivities of other products are low, which are almost zero. From Figure 4(b), the conversion of hydrogen is close to $100 \%$ when the molar ratio of hydrogen to glycerol is lower than 5.0. With the increase of the molar ratio of $\mathrm{H}_{2}$ to glycerol, the selectivity of methane increases and the selectivity of hydroxyacetone decreases. When the molar ratio of hydrogen to glycerol is higher than 5.0, the conversion of hydrogen decreases and the selectivity of hydroxyacetone decreases with the increase of molar ratio of $\mathrm{H}_{2}$ to glycerol, but the selectivity of methane is close to $100 \%$. Excess hydrogen is easy to produce a large amount of methane. Therefore, the molar ratio of hydrogen and glycerol should be controlled below 5.0. According to the relevant literature [5-7], it was found that methane has high selectivity under the condition of high molar ratio of hydrogen to glycerol and long reaction time.

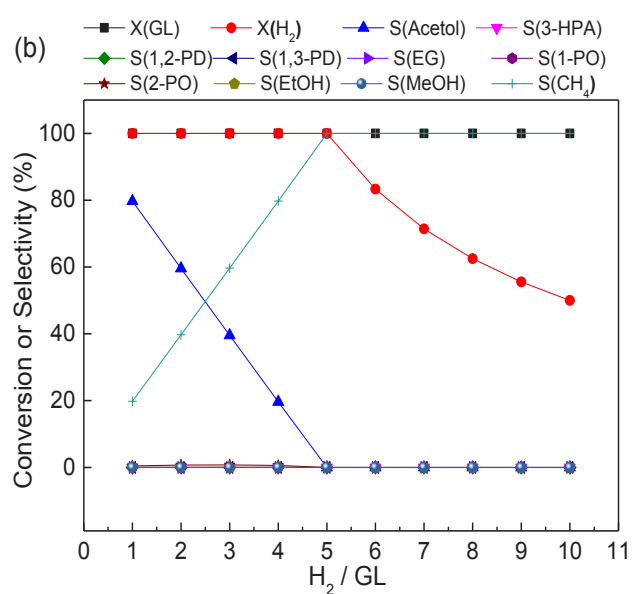

Figure 4. Effects of reaction conditions on the deep hydrogenolysis reaction system (DHS).

It is also found that pressure has little effect on the conversion of raw materials and the selectivity of products under the calculation conditions (Figure omitted). However, with the increase of reaction pressure, the selectivities of various diols and monohydric alcohols are slightly improved. Increasing the pressure is beneficial to the hydrogenolysis of glycerol to diols. 


\subsection{Comparison of calculation results}

The comparison between the calculated results of glycerol hydrogenolysis and the related experimental results is shown in Table 2. It can be seen from Table 2 that different catalysts have different product selectivity, and reaction time and reaction environment also have great influence on the selectivity of each product. For the simplified reaction system (SRS), 1,2-propanediol has high selectivity, 1,3-propanediol also has a certain amount, and the selectivity of glycol is the lowest, which is consistent with the relevant experimental results [6-8]. For the deep hydrogenolysis system (DHS), in addition to the higher content of methane, there are also a certain amount of hydroxyacetone and a small amount of isopropanol, and the selectivity of other substances is very low, which is also consistent with the relevant experimental results to some extent $[6,9]$.

Table 2. Comparison between calculation results and related experimental results

\begin{tabular}{|c|c|c|c|c|c|c|c|c|c|}
\hline \multirow{2}{*}{$\begin{array}{l}\text { Experimental conditions / } \\
\text { calculation conditions }\end{array}$} & \multirow{2}{*}{$\begin{array}{c}\text { Conversion } \\
X(\mathrm{GL}), \%\end{array}$} & \multicolumn{7}{|c|}{ Selectivity (\%) } & \multirow[b]{2}{*}{ Ref. } \\
\hline & & Acetol & 1,2-PD & 1,3-PD & EG & $\begin{array}{l}1-\mathrm{PO} \\
12-\mathrm{PO} \\
\end{array}$ & $\begin{array}{c}\mathrm{EtOH} \\
/ \mathrm{MeOH} \\
\end{array}$ & $\mathrm{CH}_{4}$ & \\
\hline $\begin{array}{l}\mathrm{Rh} / \mathrm{SiO}_{2}(\mathrm{G}-6)+\mathrm{Amberlyst} \\
393 \mathrm{~K}, 8.0 \mathrm{MPa}\left(\mathrm{H}_{2}\right), 10 \mathrm{~h}\end{array}$ & 29.3 & - & 22.6 & 5.4 & 0 & $41.3 / 17.0$ & $1.8 / 0.0$ & 12.0 & [6] \\
\hline $\begin{array}{c}\mathrm{Ru} / \mathrm{C}+\mathrm{Amberlyst}, \\
393 \mathrm{~K}, 8.0 \mathrm{MPa}\left(\mathrm{H}_{2}\right), 10 \mathrm{~h}\end{array}$ & 38.8 & & 28.8 & 0.8 & 7.4 & $28.9 / 2.4$ & $18.7 / 1.9$ & 11.2 & {$[6]$} \\
\hline $\mathrm{Re}, 393 \mathrm{~K}, 8.0 \mathrm{MPa}\left(\mathrm{H}_{2}\right), 5 \mathrm{~h}$ & 67.0 & & 38.0 & 14.0 & & $35.0 / 12.0$ & & & [7] \\
\hline $\mathrm{Pt} / \mathrm{WO}_{3}, 428 \mathrm{~K}, 12 \mathrm{~h}$ & 37.5 & & 4.0 & 32.4 & & $46.3 / 6.4$ & & & [8] \\
\hline $\begin{array}{c}\text { Thermodynamics of SRS: } \\
400 \mathrm{~K}, \quad 3.0 \mathrm{MPa}, \mathrm{H}_{2} / \mathrm{GL}=1.0\end{array}$ & 100 & & 95.5 & 4.47 & 0.03 & & $0.0 / 0.0$ & & $\begin{array}{l}\text { This } \\
\text { paper }\end{array}$ \\
\hline $\begin{array}{c}\mathrm{Ni}-\mathrm{Cu} / \mathrm{Al}_{2} \mathrm{O}_{3}, \\
493 \mathrm{~K}, 4.5 \mathrm{MPa}\left(\mathrm{N}_{2}\right), 10 \mathrm{~h}\end{array}$ & 15.8 & 38.8 & 49.3 & & & & & & {$[9]$} \\
\hline $\begin{array}{l}\text { Thermodynamics of DHS: } \\
500 \mathrm{~K}, \quad 3.0 \mathrm{MPa}, \mathrm{H}_{2} / \mathrm{GL}=3.0\end{array}$ & 100 & 39.5 & $3.5 \mathrm{E}-05$ & & & $0.026 / 0.7$ & $0.01 / 0.0$ & 59.7 & $\begin{array}{l}\text { This } \\
\text { paper }\end{array}$ \\
\hline
\end{tabular}

\section{Conclusions}

The thermodynamics of the reaction system based on different mechanism of glycerol hydrogenolysis was studied. The calculated results are compared with the experimental results. The conclusions of this study are as follows:

(1) The thermodynamic parameters of three reaction equations for glycerol hydrogenolysis to 1,2-propanediol, 1,3-propanediol and glycol were calculated. In the low temperature range below $375 \mathrm{~K}$, the equilibrium constants of 1,2-propanediol and 1,3-propanediol are close to each other. In the high temperature range above $375 \mathrm{~K}$, the order of the equilibrium constants of the diols is: 1,2-propanediol > 1,3-propanediol $>$ glycol.

(2) For the simplified reaction system of glycerol hydrogenolysis to diols, 1,2-propanediol has the highest selectivity. The optimum conditions for hydrogenolysis of glycerol to 1,2-propanediol are as follows: 400-500 K, the molar ratio of hydrogen to glycerol of 1.0-1.5 and moderate pressure.

(3) For the deep hydrogenolysis of glycerol to diols and theis further hydrogenolysis reaction system, under the calculated reaction conditions, the conversion of glycerol is always close to $100 \%$, the selectivities of methane and hydroxyacetone are high, and the selectivities of other products are low, which is consistent with the relevant experimental results.

\section{Acknowledgements}

Financial supports from Key Research Projects of Higher Education in Henan Province of China (20B480006) and Program of Processing and Efficient Utilization of Biomass Resources of Henan Center for Outstanding Overseas Scientists (GZS2018004) are gratefully acknowledged.

\section{References}

1. Almena A, Bueno L, Díez Marcos \& Martín Mariano. (2018) Integrated biodiesel facilities: review of glycerol-based production of fuels and chemicals. Clean Technologies and Environmental Policy, 20:1639-1661.

2. Kun Ouyang, Yu Huang, Haoyi Chen, Tao Li, Fahai Cao, Dingye Fang. (2011) Thermodynamic analysis of liquid phase in situ hydrogenation of glycerol for 1,3-propanediol synthesis. Frontiers of Chemical Science and Engineering, 5(1): 67-73.

3. Dasari M A, Kiatsimkul P P, Sutterlin W R, \& Suppes G J. (2005) Low-pressure hydrogenolysis of glycerol to propylene glycol. Applied Catalysis A General, 281(1-2):225-231.

4. Miyazawa T, Kusunoki Y, Kunimori K, \& Tomishige K. (2006) Glycerol conversion in the aqueous solution under hydrogen over $\mathrm{Ru} / \mathrm{C}+$ an ion-exchange resin and its reaction mechanism. Journal of Catalysis, 240(2):213-221. 
5. Montassier C, Ménézo J C, Hoang L C, Renaud C, \& Barbier J. (1991) Aqueous polyol conversions on ruthenium and on sulfur-modified ruthenium. Journal of Molecular Catalysis, 70(1):99-110.

6. Furikado I, Miyazawa T, Koso S, Shimao A, Kunimori K, \& Tomishige K. (2007) Catalytic performance of $\mathrm{Rh} / \mathrm{SiO}_{2}$ in glycerol reaction under hydrogen. Green Chemistry, 9(6):582-588.

7. Yasunori Shinmi, Shuichi Koso, Takeshi Kubota, Yoshinao Nakagawa, \& Keiichi Tomishige. (2010) Modification of $\mathrm{Rh} / \mathrm{SiO}_{2}$ catalyst for the hydrogenolysis of glycerol in water. Applied Catalysis B Environmental, 94(3-4):318-326.

8. Chaojun Y, Fan Z, Nian L, Man Y, Fei L, \& Zhili M, et al. (2018) Understanding the promotional effect of au on $\mathrm{Pt} / \mathrm{WO}_{3}$ in hydrogenolysis of glycerol to 1,3propanediol. Chinese Journal of Catalysis, 39(8):1366-1372.

9. Gandarias I, Arias P L, Sara G Fernández, Jesús Requies, Doukkali M E, \& María Belén Güemez. (2012) Hydrogenolysis through catalytic transfer hydrogenation: glycerol conversion to 1,2propanediol. Catalysis Today, 195(1):22-31. 